\title{
PHOTOGRAMMETRIC 3D INFORMATION SYSTEMS FOR THE MANAGEMENT OF MODELS OF CULTURAL HERITAGE
}

\author{
L. Corniello ${ }^{1 *}$ \\ ${ }^{1}$ University of Campania "Luigi Vanvitelli”, Department of Architecture and Industrial Design, \\ Aversa (Caserta), Italy - luigi.corniello@unicampania.it
}

Commission VI, WG VI/4

KEY WORDS: survey, photogrammetry, 3D model, cultural heritage, advanced digital processes

\begin{abstract}
:
The research on 3D photogrammetric information systems, for the management of digital models of Cultural Heritage, addresses several objectives in the field of digitization and three-dimensional modeling of heritage. The study is conducted through detailed and accurate photographic and iconographic documentation, survey and digital documentation with accessible models. The present work, therefore, proposes to document and reconstruct graphically, the historical evolution of the Hvar Tvrdalj Fortress in Croatia through a series of digital drawings, but especially $3 \mathrm{~d}$ photogrammetric modeling systems of outdoor spaces. Particular attention was paid to the digital modeling activities of the fishpond, located inside the fortified structure. The activity of representation of the Fortress of Hvar Tvrdalj was set up by providing, in an initial phase, the execution of a basic survey extended to the architectural organisms and the surrounding green space in order to define a first two-dimensional geometric model; then, in a second phase, were made the survey graphs and the consequent graphic restitution with the measurements of architectural details and the complete survey of the inner tank. The research, therefore, presents for the first time, a scientific study of photogrammetric digital survey developed through the creation of 3D digital models on a structure of great architectural and landscape interest, as well as a cornerstone of the island of Hvar for local tourism.
\end{abstract}

\section{INTRODUCTION}

The research on 3D photogrammetric information systems, for the management of digital models of Cultural Heritage, addresses several objectives in the field of digitization and three-dimensional modeling of heritage. The study is conducted through detailed and accurate photographic and iconographic documentation, survey and digital documentation with usable models.

The theme of digital modeling is of great importance, since it allows to face, according to disciplinary assumptions, such as technical-instrumental and theoretical applications, the dynamics of drawing related to both traditional and innovative digital representation. With this science the aspect concerning the visualization is determined, a fundamental element for the communication of the object examined, through which it is possible to define the final graphic rendering compatible with the purpose of the relevant activity, both relative to the knowledge of the existing and indicative for the protection and enhancement of the asset.

Three-dimensional modeling of cultural heritage starting from digital images at different scales and acquisitions with low cost tools has recently gained attention from the scientific community for the realization of innovative research and advanced digital modeling processes, due to the availability of new technologies for the recording, processing, management and visualization of 3D data (Amoruso, Apollonio, Remondino, 2010).

The present work, therefore, aims to document and reconstruct graphically, the historical evolution of the Fortress of Hvar Tvrdalj in Croatia through a series of digital drawings, but especially $3 \mathrm{~d}$ photogrammetric modeling systems of outdoor spaces. Particular attention was paid to the digital modeling activities of the fishpond, located inside the fortified structure.

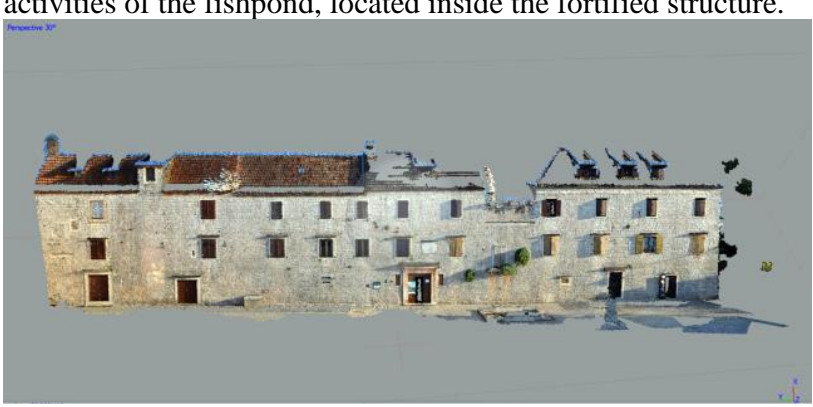

Figure 1. Point of cloud made with photogrammetric representation software. Main prospect of the Tvrdalj Fortress.

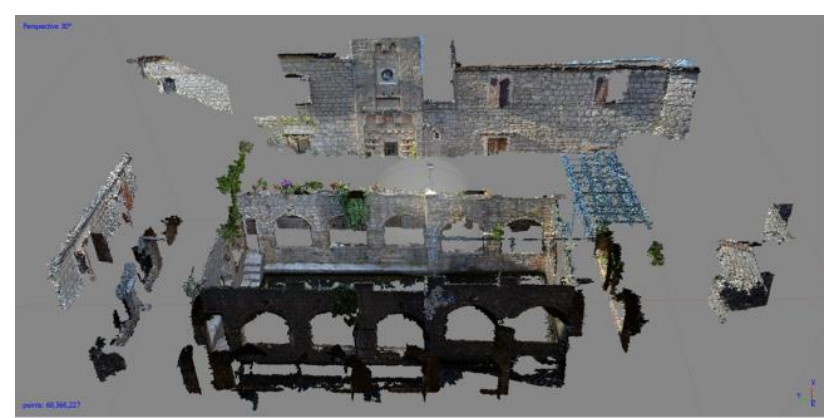

Figure 2. Point of cloud made with photogrammetric representation software for the central building of the Tvrdalj Fortress in Hvar.

\footnotetext{
* Corresponding author
} 


\section{METHODOLOGIES OF SURVEY AND GRAPHIC REPRESENTATION}

In order to elaborate 3D digital models it is useful to clarify the scientific dynamics that regulate the relationship between architecture and graphic representation. The critical description of architecture, starting from the graphic reading of the typological imprints of the constructions of the past and the morphological configurations, with reference to the discipline of drawing, makes explicit the awareness of the scientific and cultural foundations of representation methods to understanding architecture.

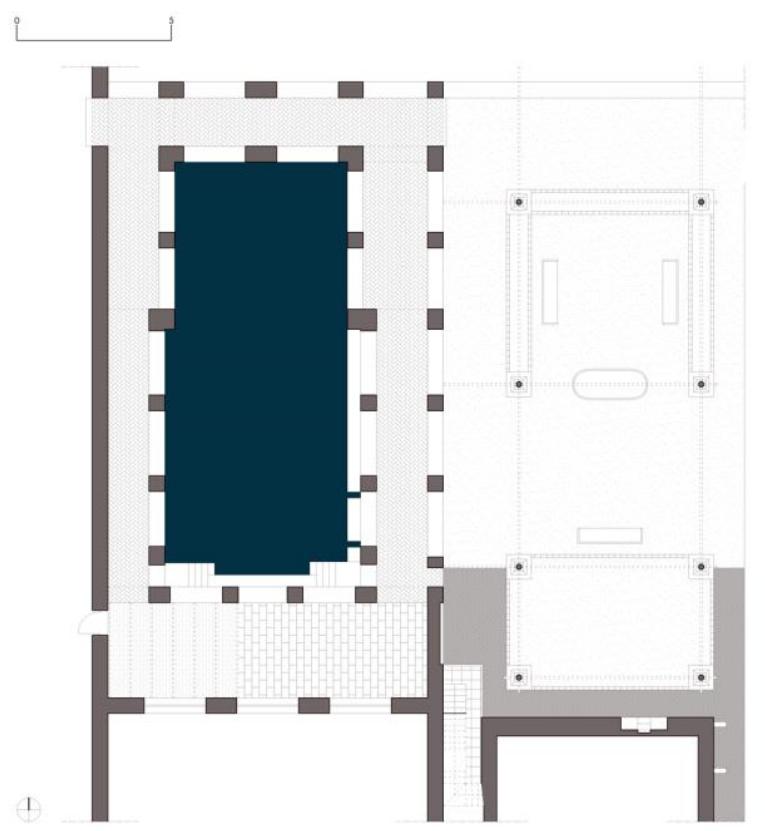

Figure 3. The Tvrdalj Fortress in Hvar. General Plan +1.00 .

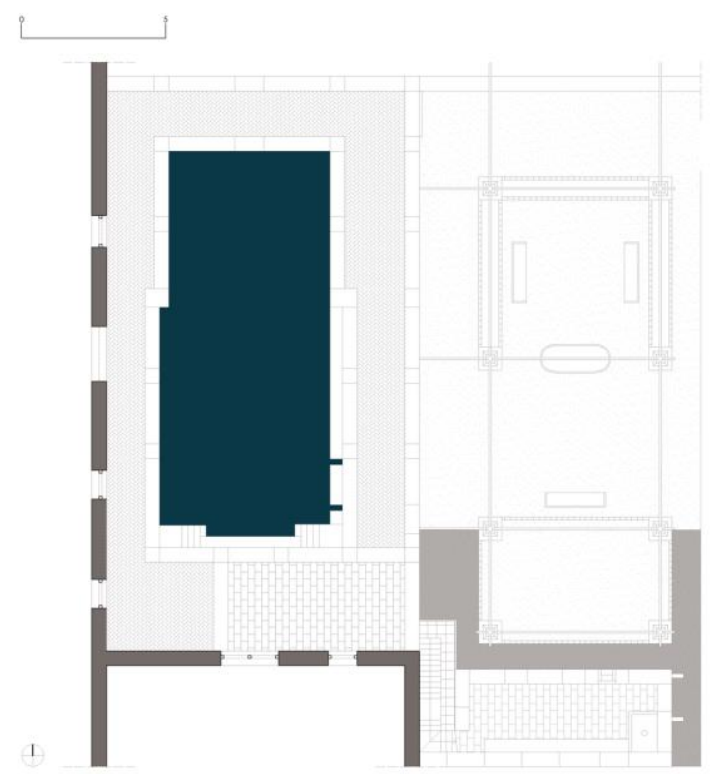

Figure 4. The Tvrdalj Fortress in Hvar. General Plan + 4.00.
In order to develop three-dimensional models for documentation purposes and graphic representations at knowledge, it is necessary that the final product includes some specific characteristics. Of considerable importance are the precision and reliability of the details, especially in areas of discontinuity, when changing materials or changing geometry. In the field just described, the containment of modelling costs through the use of low cost tools and software and a rapid data acquisition time, also through the adaptability of the survey techniques to the research context, are of considerable interest in order to ensure a realistic return even at close range.

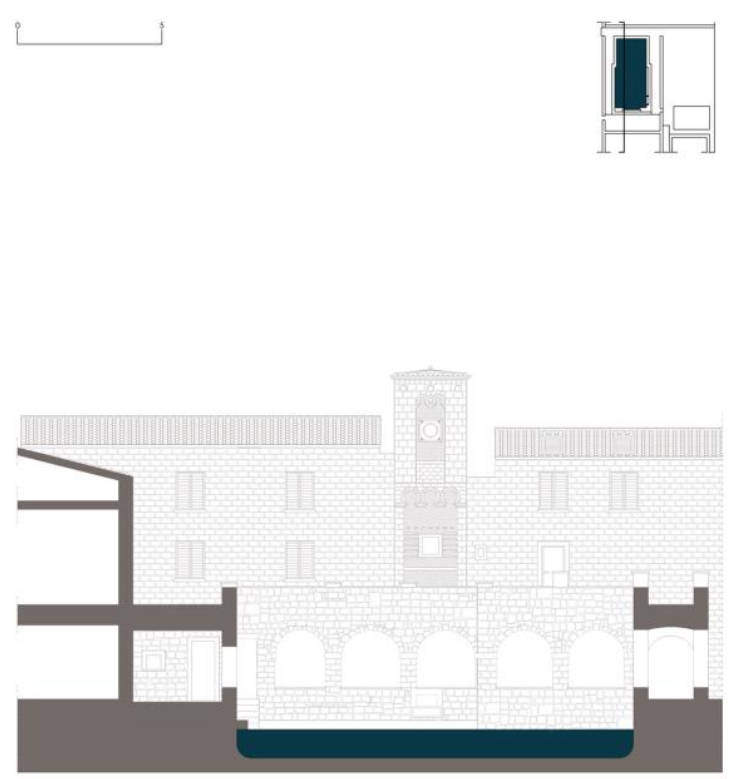

Figure 5. The Tvrdalj Fortress in Hvar. The longitudinal section to the east on the water pool.

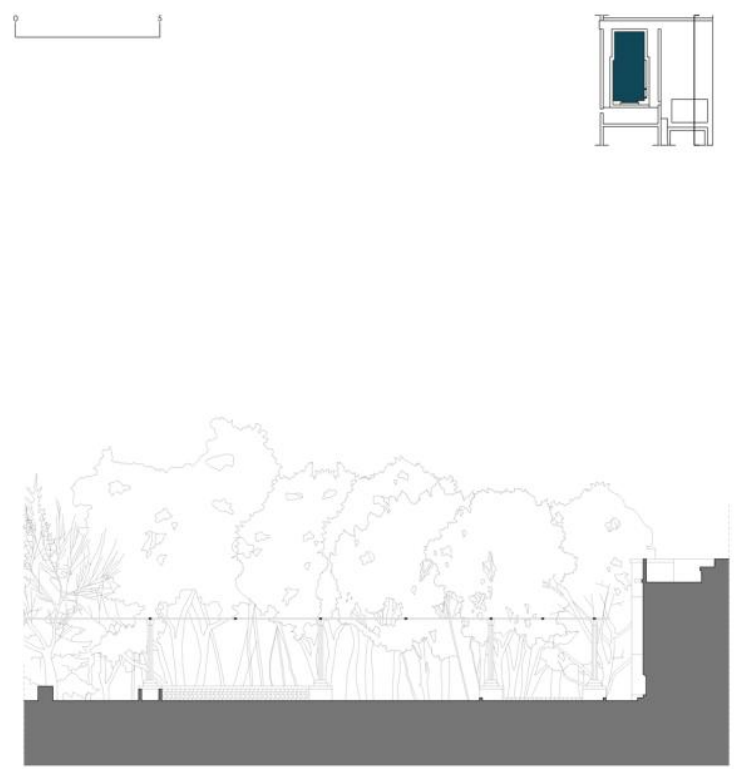

Figure 6. The Tvrdalj Fortress in Hvar. Longitudinal section on the garden. 


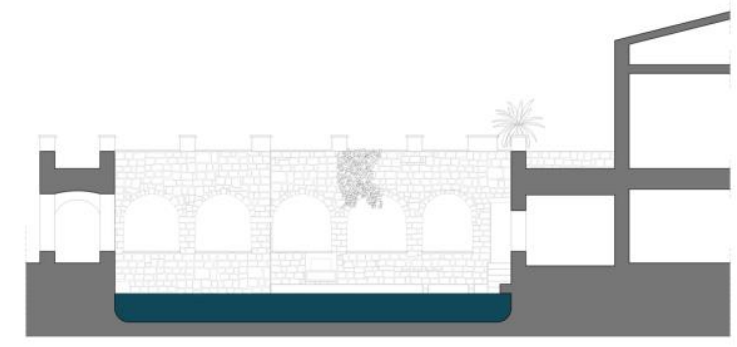

Figure 7. Longitudinal section eastwards on the water pool.
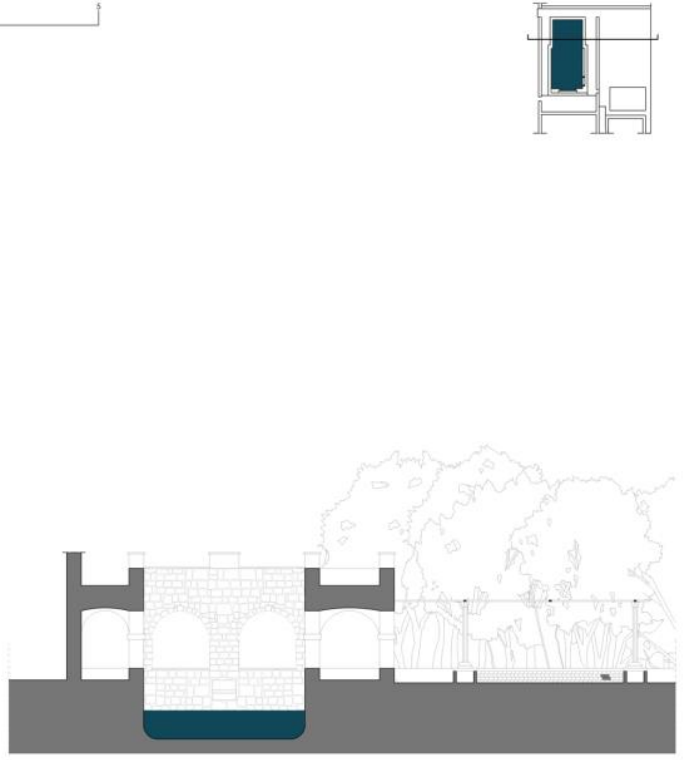

Figure 8. Northern section on the water pool.

New information technologies applied to the knowledge of basic geometry become a tool of restitution, analysis, information of the Hvar Tvrdalj Fortress.

In the illustrated graphic system, the drawing of architecture, that is the practical one oriented to model the object as a form, covers the main critical and theoretical exercise of method for digital technologies by defining the geometrical issues necessary for the creation of virtual models.

In this sense, the method of orthogonal double projections, parallel projections and central projections constitute the explanation of its scientific features through their inheritability to bring out the thematic and ideal contents of architecture.
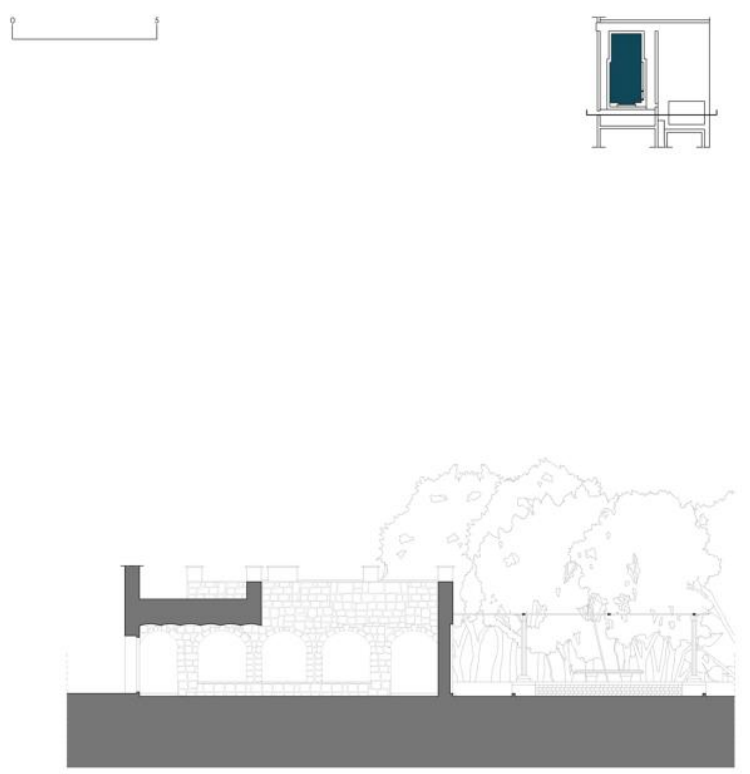

Figure 9. Northward section on the secondary building block.
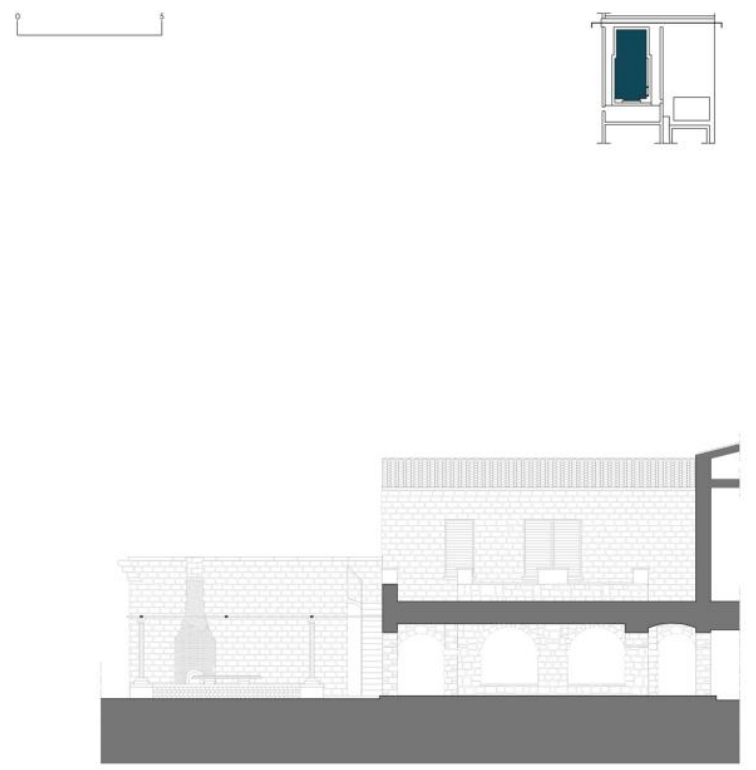

Figure 10. South-facing section on the porch with brick arches.

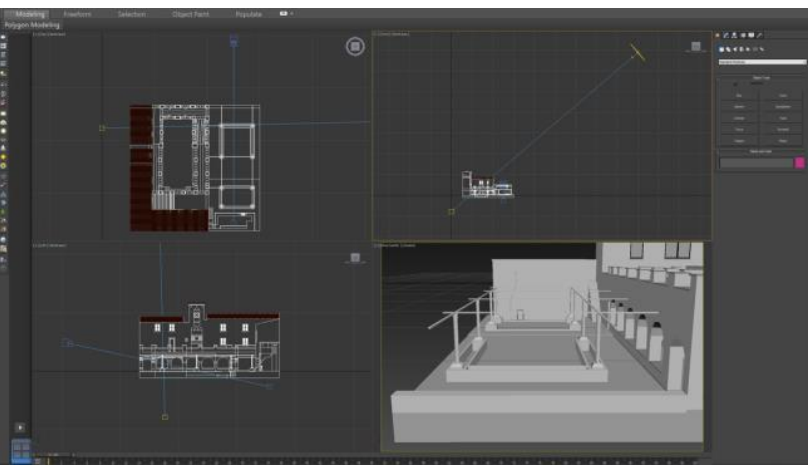

Figure 11. Three-dimensional modeling with digital software for 3D model visualization. Geometric analysis of the garden. 


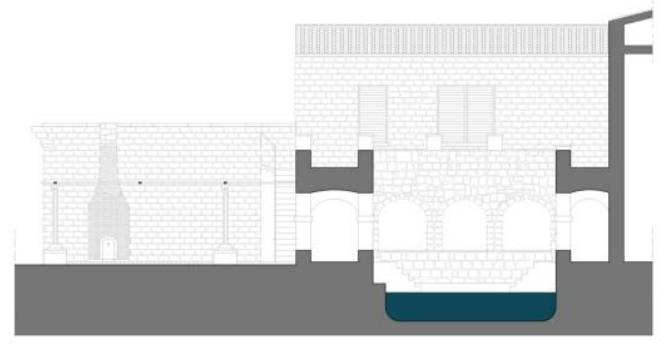

Figure 12. Southern sections on the water pool.

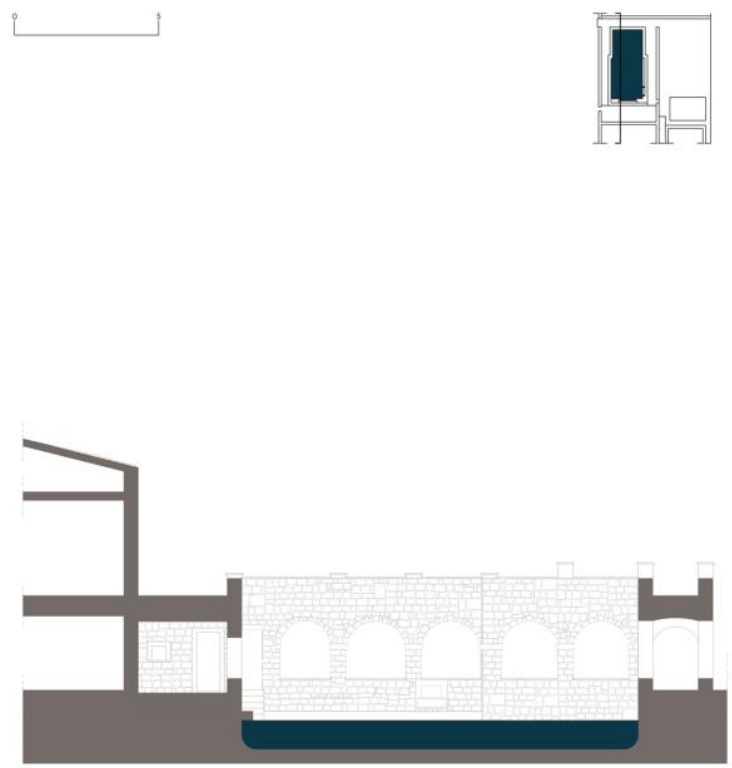

Figure 13. Longitudinal section westwards on the water pool.

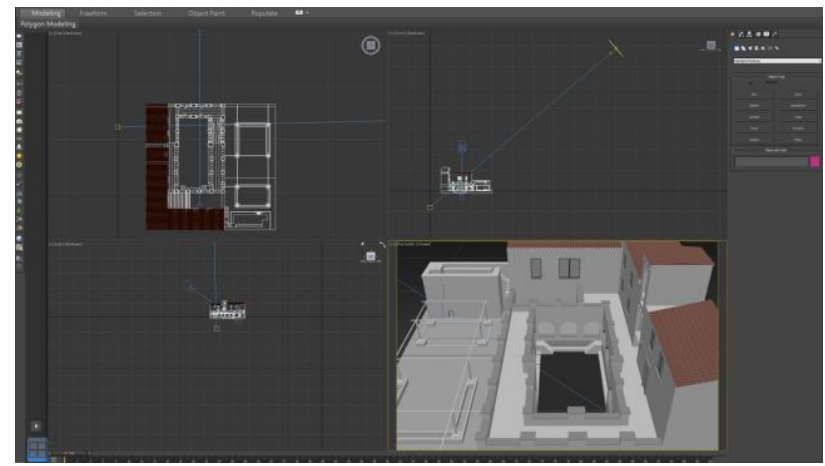

Figure 14. Three-dimensional modeling with digital software to visualize the 3D model. Geometric analysis of the water pool.
Digital representation, as well the implicit creation of models, besides playing a graphic role of three-dimensional reproduction of the object, is an instrument for verifying the congruence of conventional representations, such as plans, sections and elevations.

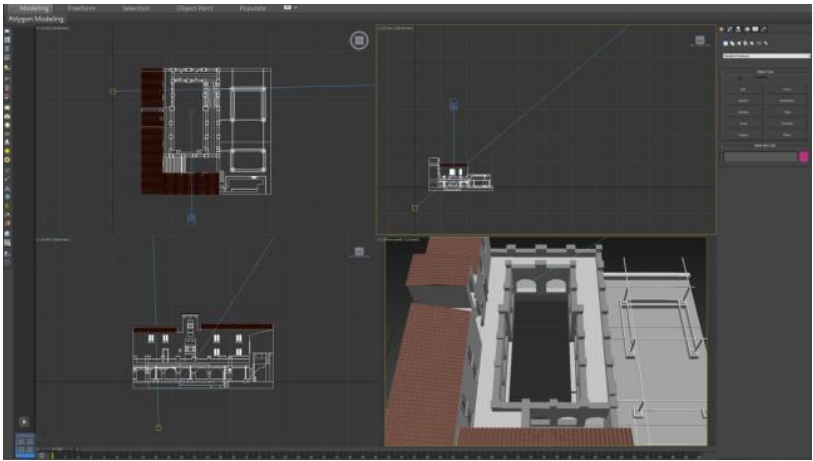

Figure 15. Three-dimensional modeling with digital software for the visualization of the 3D model. Geometric analysis of the system of the main building shells.

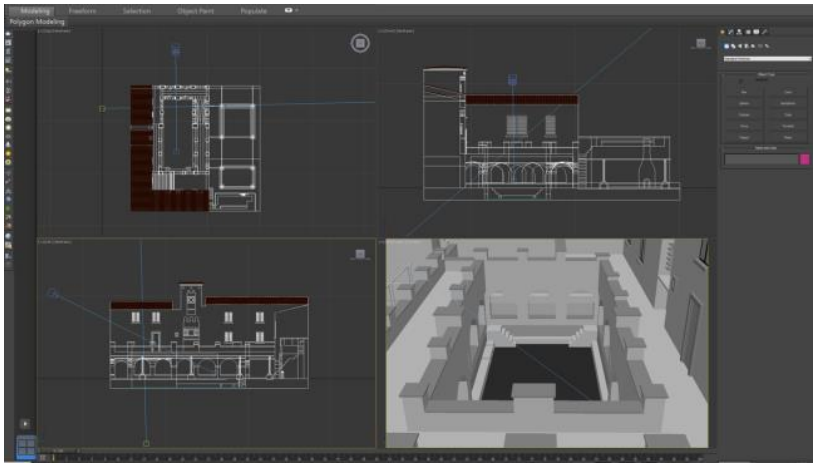

Figure 16. Three-dimensional modeling with digital software for 3D model visualization. Geometric analysis of the roof system of the brick arbour.

\section{THE CONSTRUCTION OF THE 3D DIGITAL MODEL}

The model is an ideal icon of reality and, as far as morphology is concerned, it shows all the characteristics indicated by the drawing, specifying in the best way possible its shape and peculiarities, representing and manipulating real elements through complex simulations. These computer activities determine a dynamic representation of three-dimensional data using articulated visualization techniques and using materials, lights, colors, tends to reproduce the characteristics of the real world. Of great interest is the primitive phase of modeling, the activity of three-dimensional transformation of two-dimensional graphs, which allows an immediate visualization of geometric shapes and basic volumes. These physical models constitute both geometrical configurations to determine the volumes and the bases with which to interact through photo-modeling.

As is well known, in order to develop interactive digital models, basic knowledge about data acquisition through instrumental surveys that can be carried out with passive sensors is necessary, when data are acquired through images with inexpensive and very drinkable systems. At the same time, it is possible to intervene through surveys with active sensors where 


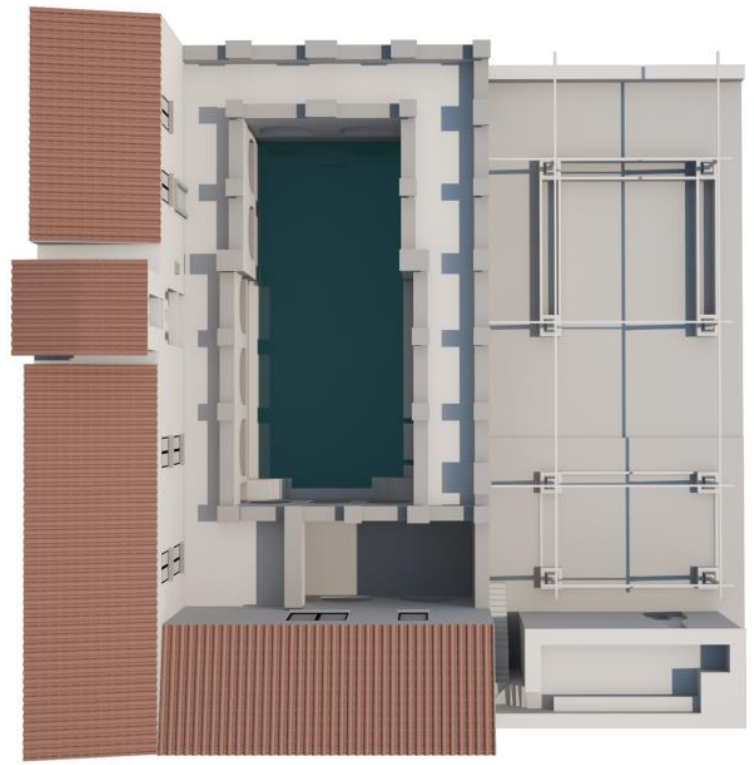

Figure 17. The Tvrdalj Fortress in Hvar. 3D digital model realized by digital survey and parametric software. Zenith view of the whole complex and the garden.

the active instruments detect distances and directly provide three-dimensional measurements of the detected object.

For the documentation and cataloguing of cultural heritage we have a series of instruments for data acquisition (Manfredini, Remondino, 2010).

The activity of representation of the Fortress of Hvar Tvrdalj was set up by providing, in an initial phase, the execution of a basic survey extended to the architectural organisms and the surrounding green space in order to define a first twodimensional geometric model; then, in a second phase, were made the survey graphs and the consequent graphic restitution with the measurements of architectural details and the complete survey of the inner tank.

In addition, an adequate and complete photographic documentation was carried out, as well as investigations of the scarce bibliographic, archival and iconographic sources.

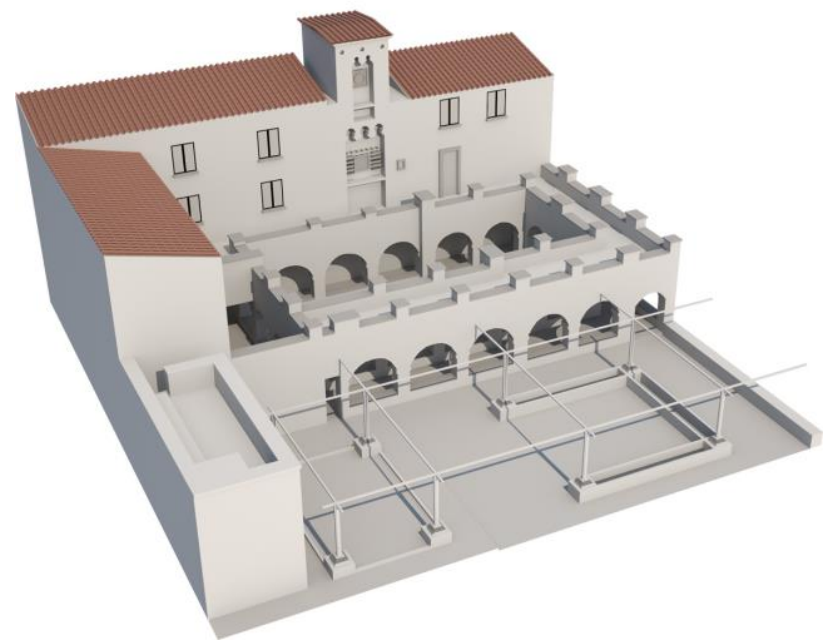

Figure 18. The Tvrdalj Fortress in Hvar. 3D digital model realized by digital survey and parametric software. View north west.

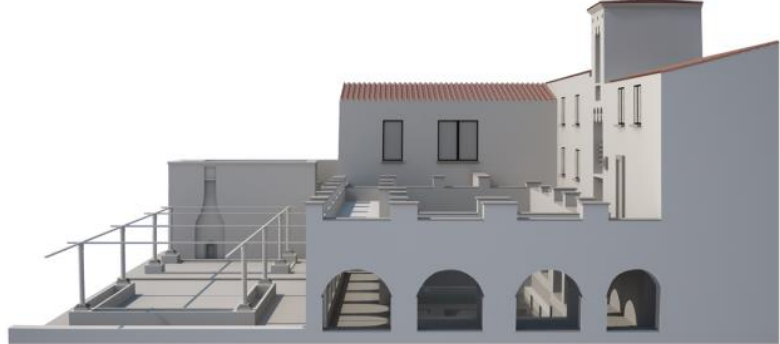

Figure 19. The Tvrdalj Fortress in Hvar. 3D digital model realized by digital survey and parametric software. View to the south.

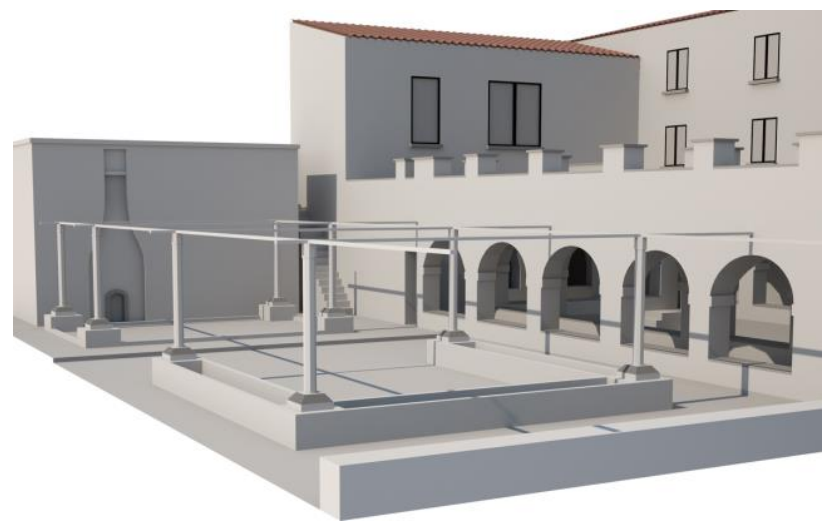

Figure 20. The Tvrdalj Fortress in Hvar. 3D digital model realized by digital survey and parametric software. Detail of the garden, south - west view.

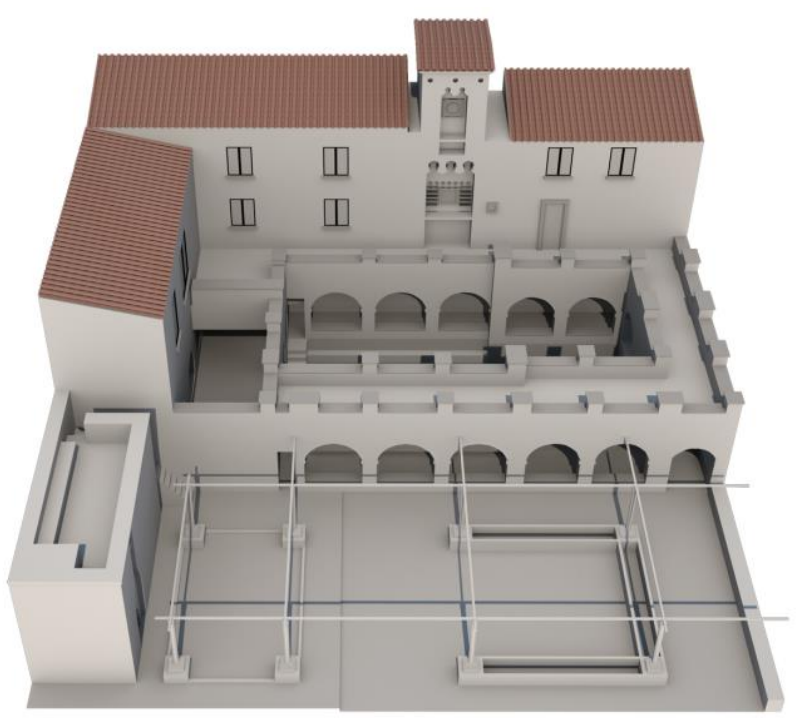

Figure 21. The Tvrdalj Fortress in Hvar. 3D digital model realized by digital survey and parametric software. View to the west. 
Particular attention has been paid to the concept of the photographic image which, besides representing an absolute database value that can be drawn from even after the survey phase, constitutes a dynamic knowledge tool.

It is evident the possibility of interpolating this static figurative data with instrumental information technology elements deriving from the technological evolution of recent times.

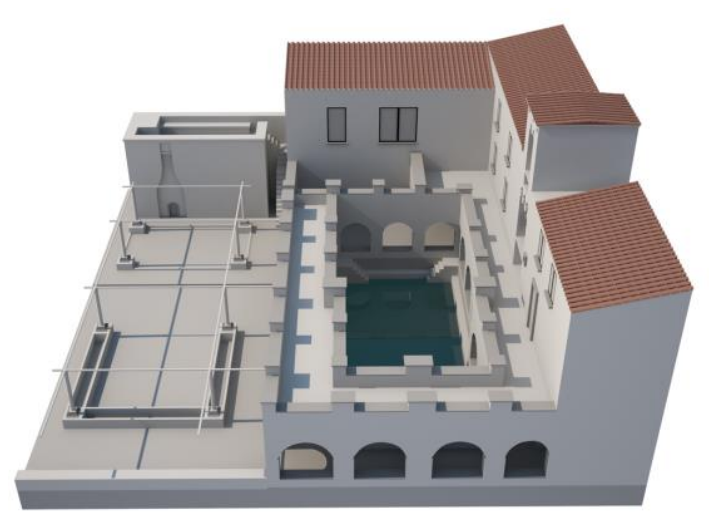

Figure 22. The Tvrdalj Fortress in Hvar. 3D digital model realized by digital survey and parametric software. View to the south.

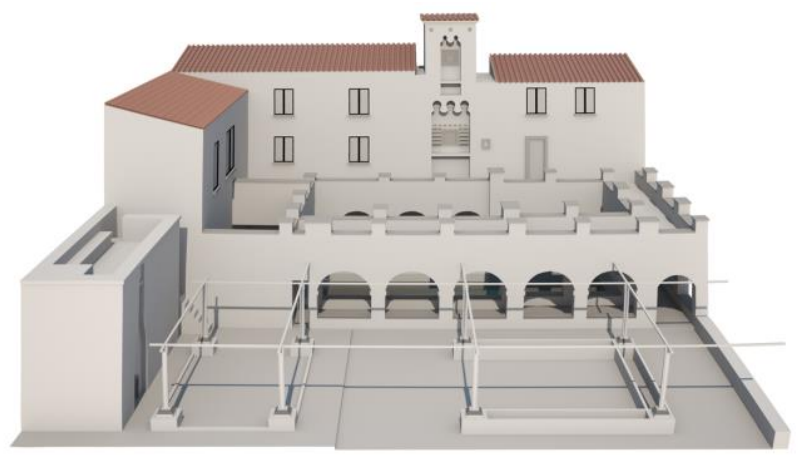

Figure 23. The Tvrdalj Fortress in Hvar. 3D digital model realized by digital survey and parametric software. View to the west.

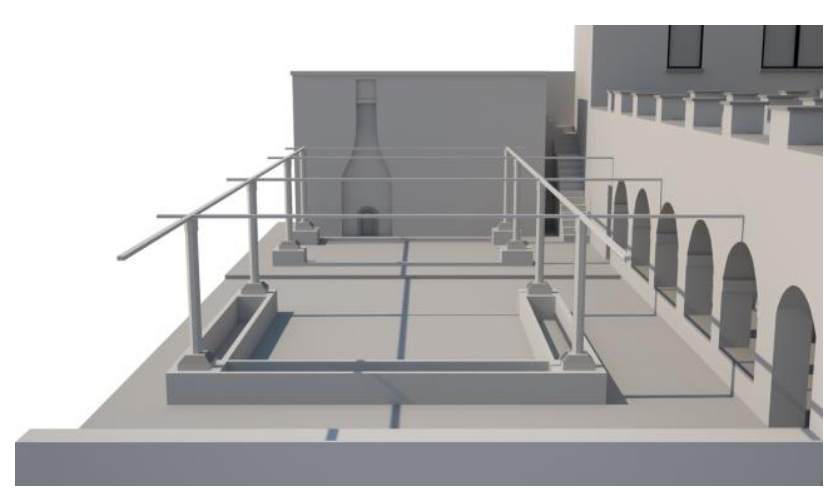

Figure 24. The Tvrdalj Fortress in Hvar. 3D digital model realized by digital survey and parametric software. Particular of the garden, south view.
In parallel to the availability of a wide variety of digital images, in the last few years, numerous photogrammetric software with new automated procedures for image orientation and the generation of digital surface models have been developed. In addition, the relevant digital tools provide new technical functionalities for the management and analysis of the collected photogrammetric data and allow direct digital processing.

\section{3D MODELS OF CULTURAL HERITAGE}

The digital modeling of the Hvar Tvrdalj Fortress, a Renaissance fortified villa built by the humanist Petar Hektorovic (1487-1572), which includes a lush garden, a dovecote and a fishpond surrounded by arcades where mullet swims still today, made it possible to integrate the disciplinary skills of architectural drawing with the mathematical numerical bases of the latest generation software in order to develop questionable and manageable $3 \mathrm{D}$ photogrammetric models in terms of conservation and protection.

As is well known, photogrammetry is the science that makes it possible to obtain accurate measurements from photographs by transforming two-dimensional information into threedimensional measurements (Manfredini, Remondino, 2010).

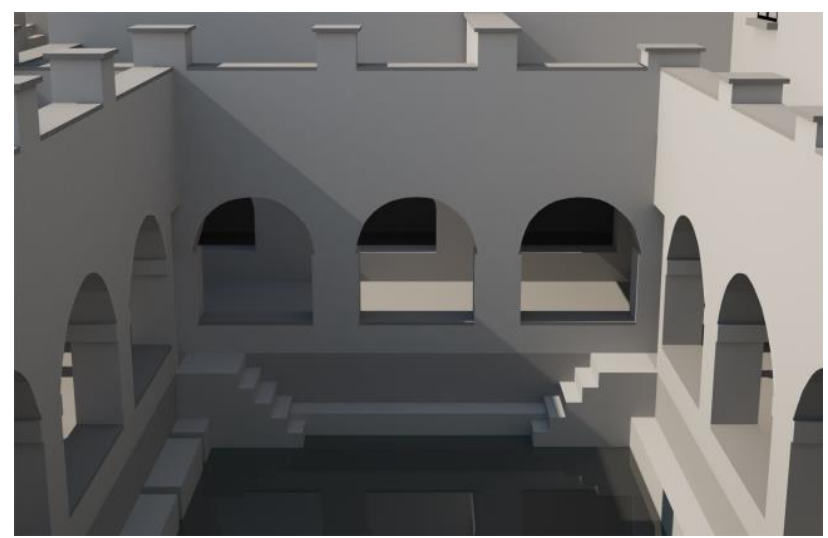

Figure 25. The Tvrdalj Fortress in Hvar. 3D digital model realized with digital survey and parametric software. Particular of the water pool, south view.

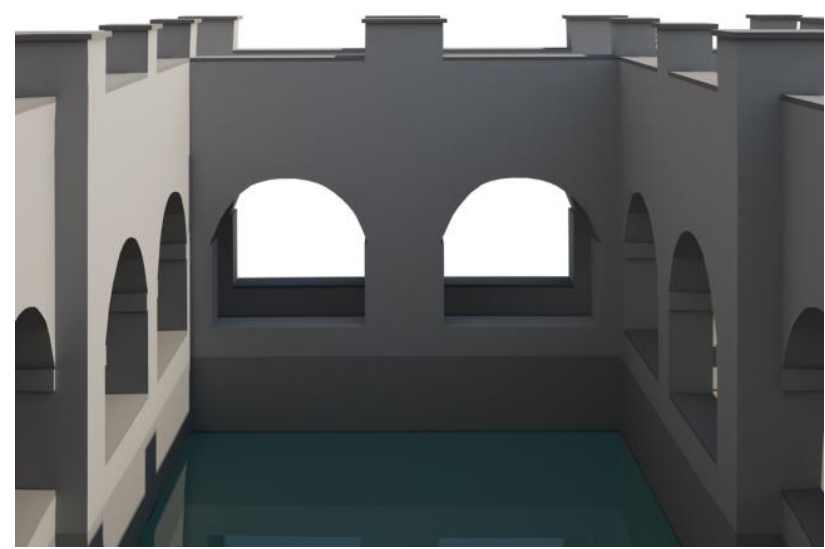

Figure 26. The Tvrdalj Fortress in Hvar. 3D digital model realized by digital survey and parametric software. Particular of the water pool, north view. 
For the digital restitution of cultural heritage, photogrammetry plays a role of considerable interest, since the images taken from digital cameras contain the information for the realization of models, the survey campaign is rapid and reduced to the shooting of photographic images often at low cost.

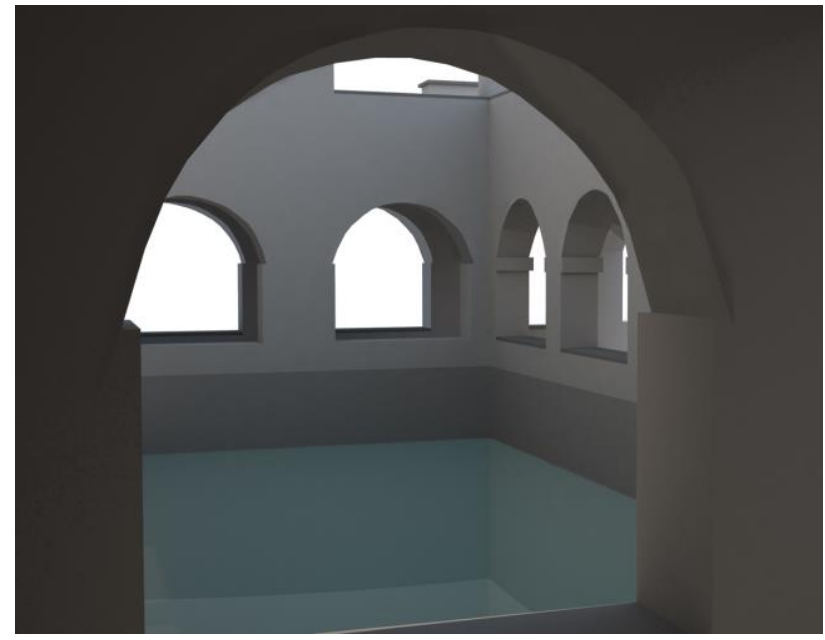

Figure 27. The Tvrdalj Fortress in Hvar. 3D digital model realized by digital survey and parametric software. Particular of the water pool and the system of arches and vaults, view to the east.

\section{THE PHOTOGRAMMETRIC TECHNOLOGY FOR 3D REPRESENTATION}

Photogrammetry, therefore, in the context of this applied research, has the task of establishing a graphic and geometrical relationship between the images taken on site and the object of relief in a photographic shot.

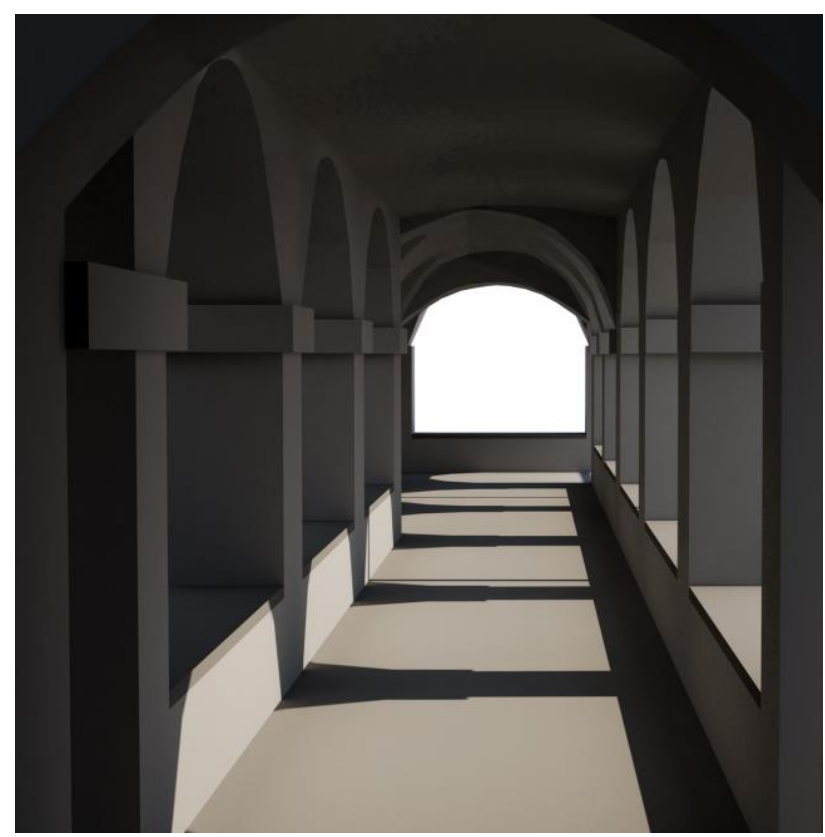

Figure 28. The Tvrdalj Fortress in Hvar. 3D digital model realized by digital survey and parametric software. Particular of the eastern corridor and the system of arches and vaults.
The photogrammetric technique allows, therefore, to determine technical information to make metric measurements on the size, shape and position of the object starting from measurements taken on images taken from both fixed and mobile supports.

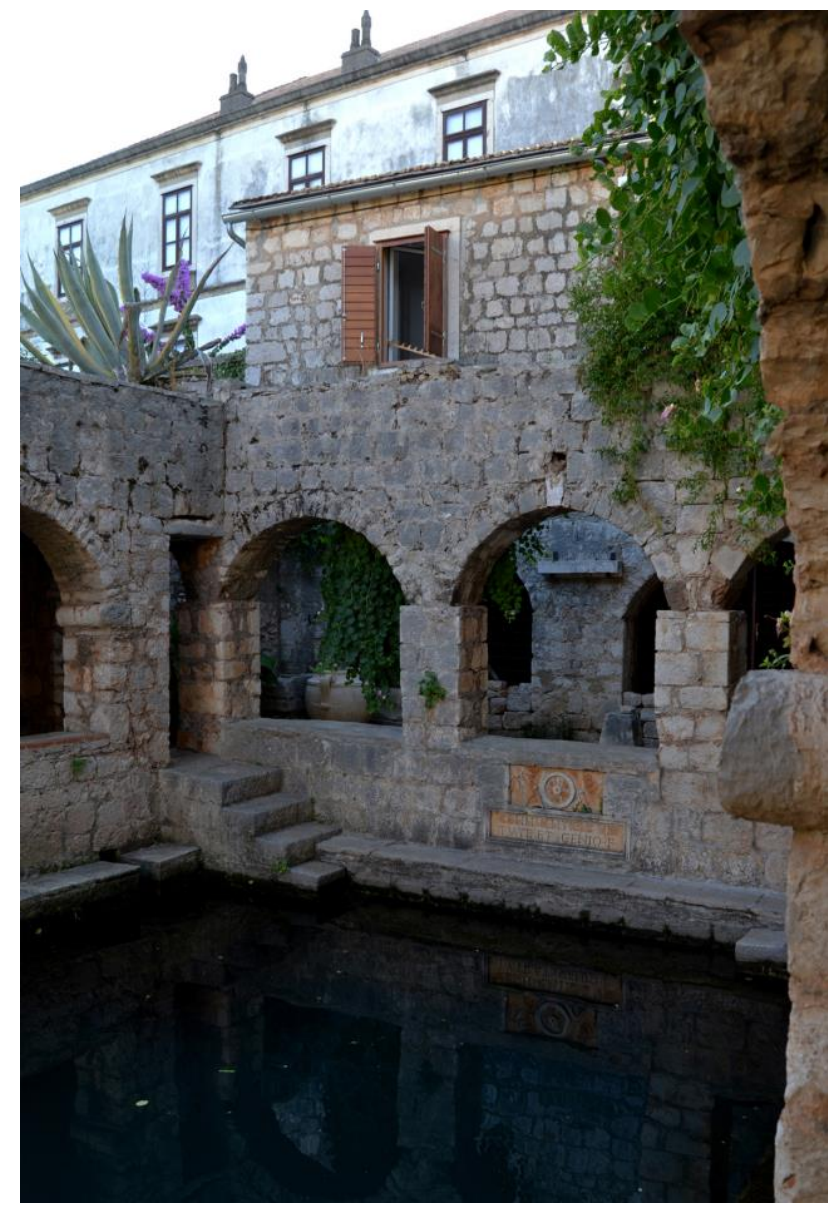

Figure 29. The Tvrdalj Fortress. View to the south - east.

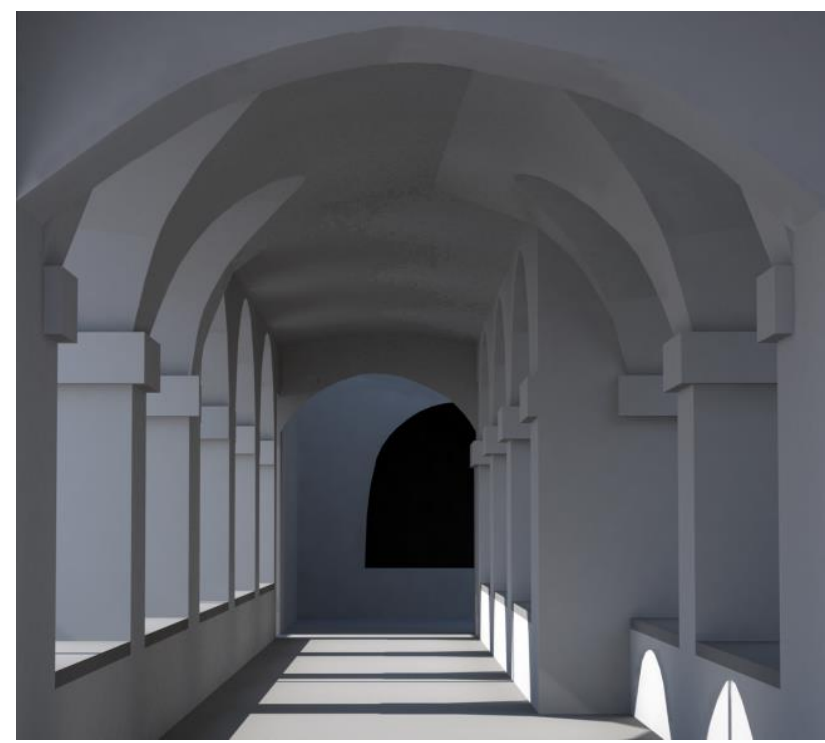

Figure 30. The Tvrdalj Fortress in Hvar. 3D digital model realized by digital survey and parametric software. Particular of the western corridor. View to the south. 


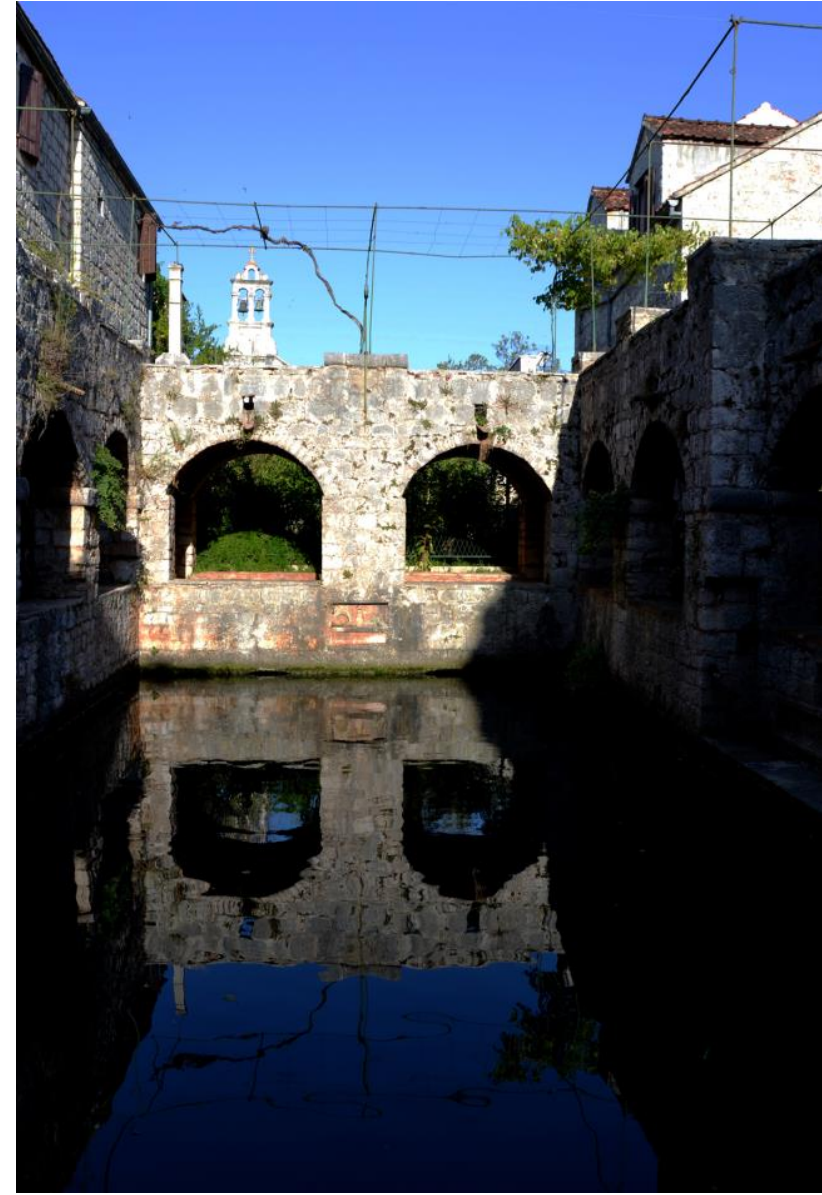

Figure 31. The Tvrdalj Fortress in Hvar. View to the north.

It is useful, for the present research, to mention the field of passive optical sensors, as instruments such as cameras that are used to capture the reflection of natural light on the surface of the object to be detected and, when using at least two images with two different points of view, they trigger a stereoscopic vision of a surveying object similar to what happens in human vision.

\section{CONCLUSIONS}

Digital modeling through photogrammetric software of the Hvar Tvrdalj Fortress has allowed the scientific documentation in order to create an interactive database. The interaction between the geometric model and the data collected, allowed the interrogation of the digital model through the use of $3 \mathrm{D}$ parametric software, both for graphic visualization and to plan conservation and enhancement of the asset. The research, therefore, presents for the first time, a scientific study of photogrammetric digital survey developed through the creation of 3D digital models on a structure of great architectural and landscape interest, and a cornerstone of the island of Hvar for local tourism.

\section{ACKNOWLEDGEMENTS}

The authors would like to thank Ordnance Survey GB (https://www.ordnancesurvey.co.uk) and 1Spatial (https://1spatial.com/) for sponsoring the publication of this paper.

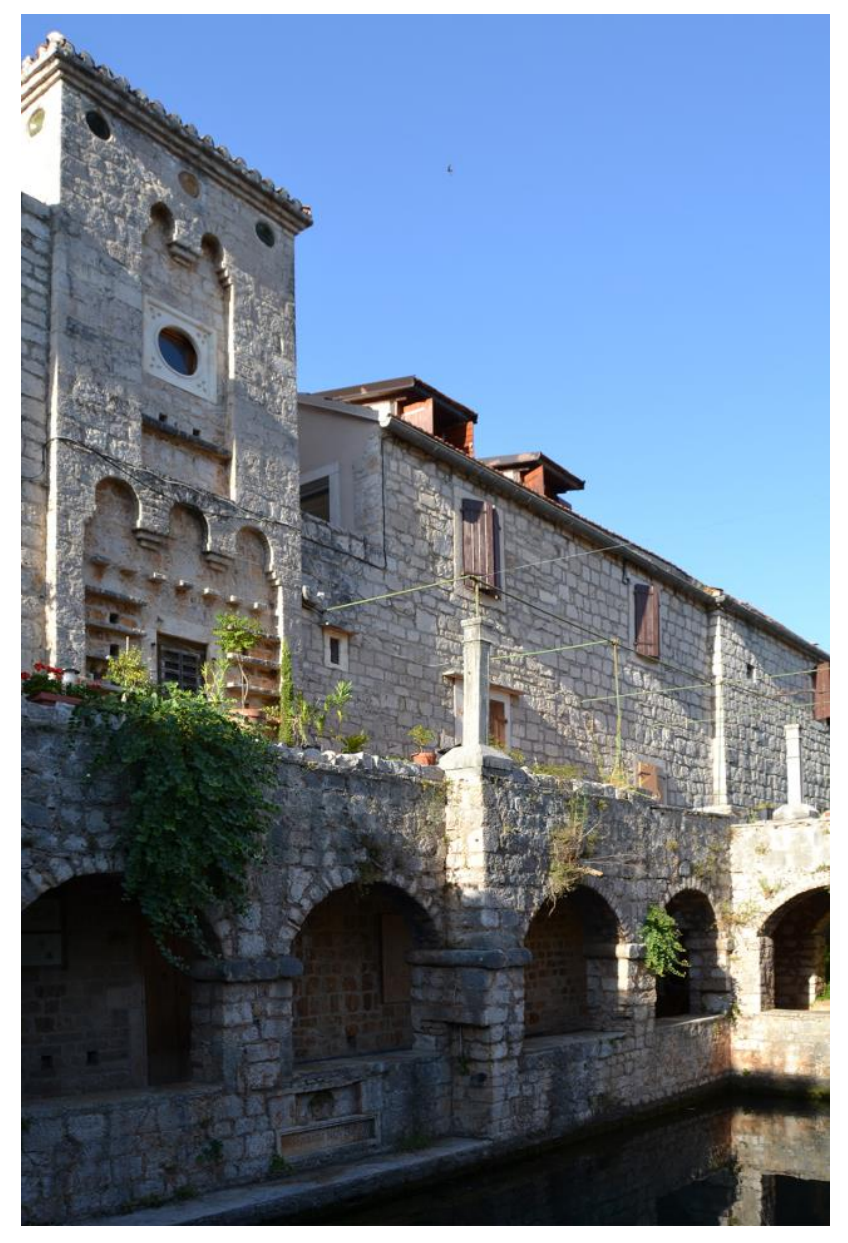

Figure 32. The Tvrdalj Fortress in Hvar. View of the interior elevation and the water basin to the north - west.

\section{REFERENCES}

Amoruso, G., Apollonio, F., I., Remondino, F., 2010, Caratterizzazione strumentale di sensori attivi a tempo di volo e a triangolazione. Utilizzo di laser scanner su superfici marmoree di epoca romana, Scuola Normale di Pisa.

Apollonio, F., I., 2010, La modellazione digitale, Bologna, Clueb.

Barba, S., Cardone, V., 2013, Modelli grafici dell'architettura e del territorio, Santarcangelo di Romagna, Maggioli.

Bianchini, C., 2011, Rilievo Modellazione e Studio Geometrico delle Cupole, Roma, Edizioni PreProgetti.

Brusaporci, S., 2007, Modelli interpretativi dell'architettura medievale, L'Aquila, Arkhè.

Corniello, L., 2019, 3D surveying and 3D reconstruction of architecture of the Royal Park of Tirana. In: The International Archives of the Photogrammetry, Remote Sensing and Spatial Information Sciences, XLII-4/W18, 241-246, 2019

Manfredini, A., M., Remondino, F., 2010, Modellazione 3D da immagini. Pipeline fotogrammetrica, Scuola Normale di Pisa. 